\title{
Subaxial Lordosis Loss and Influence Factors After Posterior Atlantoaxial Fusion
}

\section{Shaoqiang Liu ( $\nabla$ mengzicarson@163.com )}

Fuzhou Second Hospital Affiliated to Xiamen University https://orcid.org/0000-0002-4778-1495

\section{Boling Liu}

Fuzhou Second Hospital Affiliated to Xiamen University

\section{Guiqing Liang}

Fuzhou Second Hospital Affiliated to Xiamen University

\section{Qiyong Chen}

Fuzhou Second Hospital Affiliated to Xiamen University

\section{Huafeng Wang}

Fuzhou Second Hospital Affiliated to Xiamen University

\section{Yuhan Lin}

Fuzhou Second Hospital Affiliated to Xiamen University

\section{Research Article}

Keywords: Atlantoaxial fusion, Subaxial lordosis, Cervical sagittal balance, Factor analysis

Posted Date: August 17th, 2021

DOl: https://doi.org/10.21203/rs.3.rs-800835/v1

License: (c) (1) This work is licensed under a Creative Commons Attribution 4.0 International License. Read Full License

Version of Record: A version of this preprint was published at Journal of Orthopaedic Surgery and Research on March 28th, 2022. See the published version at https://doi.org/10.1186/s13018-022-030776. 


\section{Abstract}

\section{Summary of Background Data:}

Cervical sagittal balance, an important evaluation index of cervical physiological function and surgical efficacy. Subaxial kyphosis after atlantoaxial fusion is negatively associated with worse clinical outcome and higher incidence of lower cervical disc degeneration.

\section{Objectives:}

This study aimed to confirm the factors that influence subaxial lordosis loss after posterior atlantoaxial fusion.

\section{Methods:}

We performed a retrospective review of all patients following posterior C1-C2 fusion for atlantoaxial dislocation between January 2015 and December 2017. All charts, records, and imaging studies were reviewed for each case, and preoperative, immediate postoperative, and final follow-up plain films were evaluated. Comparing final follow-up and preoprative C2-C7 angle, patients were divided into two groups for further comparison: subaxial lordosis loss group and subaxial lordosis increase group.

\section{Results:}

A total of 18 patients were included in the review, with an average radiographic follow-up of $8.4 \pm 3.7$ months (range, 6 to 17 months). Subaxial lordosis loss was observed in 5 cases (27.8\%) at the final follow-up, whereas 13 cases had an increase of subaxial lordosis. The cervical sagittal parameters of preoperative and final follow-up between two groups were compared, the preoperative $\mathrm{C} 2-\mathrm{C} 7$ angle of the subaxial lordosis loss group was bigger than the subaxial lordosis increase group $\left(27.6^{\circ} \pm 10.5^{\circ}\right.$ vs $10.5^{\circ}$ $\pm 10.5^{\circ}, P<0.05$ ), but there was no statistical difference in other parameters. Univariate chi-square analysis showed that reduction of subaxial lordosis after posterior atlantoaxial fusion was associated with preoperative $\mathrm{C} 2-\mathrm{C} 7$ angle $\geq 20^{\circ}\left(X^{2}=4.923, P=0.026\right)$. However, Logistic regression analysis showed that the preoperative $\mathrm{C} 2-\mathrm{C} 7$ angle $\geq 20^{\circ}$ was not an independent risk factor ( $\left.\mathrm{OR}=0.147, \mathrm{P}=0.225\right)$.

\section{Conclusion:}

Our study demonstrates that subaxial lordosis loss may occur after posterior atlantoaxial fusion, and preoperative $\mathrm{C} 2-\mathrm{C} 7$ angle $\geq 20^{\circ}$ was a risk factor of postoperative loss of subaxial lordosis.

\section{Introduction}

Posterior atlantoaxial fusion is the main surgical method for the treatment of atlantoaxial instability or dislocation. It has achieved good clinical results and fusion rate ${ }^{[1]}$. However, some patients after atlantoaxial fusion may develop loss of normal lordotic curvature of the cervical spine, straight cervical 
alignment, kyphotic deformity, and even swan neck deformity, accompanying with anterior moving of the inferior articular process, tear of the joint capsule, increased height between spinous processes, resulting in subluxation ${ }^{[1-3]}$. Loss of subaxial lordosis often refers to reduction of lower cervical lordosis (C2-C7 angle) or increase of kyphosis after surgery ${ }^{[4-6]}$.

Cervical sagittal balance, an important evaluation index of cervical physiological function and surgical efficacy, has received increasing attention recently ${ }^{[7]}$. Studies found that cervical sagittal alignment is related to postoperative outcomes for patients receiving multilevel cervical posterior fusion, and the severity of disability increases with positive sagittal malalignment following surgical reconstruction ${ }^{[8]}$. Loss of subaxial lordosis after posterior atlantoaxial fusion also has some influence on clinical outcome. Subaxial kyphosis after atlantoaxial fusion is negatively associated with worse clinical outcome and higher incidence of lower cervical disc degeneration ${ }^{[9]}$. Subaxial kyphosis or segmental instability after atlantoaxial fusion in patients with rheumatoid arthritis may result in secondary myelopathy, requiring reoperation ${ }^{[10,11]}$. In this study, we measured measure the changes of cervical sagittal parameters and evaluated the related factors after posterior atlantoaxial fusion.

\section{Methods}

\subsection{Patient recruitment}

Following institutional review board (IRB) approval, we evaluated the retrospectively collected singleinstitute database of patients who had posterior atlantoaxial fusion for atlantoaxial dislocation between January 2015 and December 2017. Among those patients, we applied the following inclusion criteria to identify the study cohort: (1) patients diagnosed with atlantoaxial dislocation, (2) patients with Wang classification $^{[12]}$ Type I (instability) and Type II (reducible dislocation), (3) patients who had a minimum radiographic follow-up of 6 months, and (4) patients who were treated with the same standard posterior reduction and $\mathrm{C} 1-\mathrm{C} 2$ fixation. In addition, the following exclusion criteria were applied: (1) patients with posterior or vertical atlantoaxial dislocation, (2) patients with occipitocervical junction deformity, such as basilar invagination, (3) patients with cervical tuberculosis, infection or tumor, (4) patients with ankylosing spondylitis, (5) patients with prior cervical spine surgery, and (6) patients with severe medical comorbidity.

Applying these criteria yielded a total of 18 patients that were included in our final analysis. There were 8 males and 10 females with an average age of $49.6 \pm 13.7$ years (range, 25 to 72 years). Among the patients, 15 had transverse ligament loosen, 2 os odontoideum, and 1 rheumatoid polyarthritis. The study is a retrospective radiographic analysis.

\subsection{Surgical techniques}

Types I and II atlantoaxial dislocation were relatively easily fixed and fused in the reduced position from a posterior approach. Through a midline incision, we exposed the posterior arch of the atlas and the lamina of C2. The vessels and nerve roots of C2 were pulled caudally. The junction between the lateral mass and 
the inferior arch of $\mathrm{C} 1$ was exposed. Then we visualized and palpated the pedicle of $\mathrm{C} 1$. A point was opened with a burr. The pedicle of $\mathrm{C} 1$ was prepared with a 2.5- $\mathrm{mm}$ drill bit. After tapping a $3.5 \mathrm{~mm}$ pedicle screw (usually $28-30 \mathrm{~mm}$ in length) was inserted into each pedicle. Next, the vessels and nerve roots of $\mathrm{C} 2$ were retracted cephalad to expose the superior and internal aspect of the isthmus of $\mathrm{C} 2$. The $\mathrm{C} 2$ pedicle screw (diameter, $3.5 \mathrm{~mm}$; length, 22-26 mm) were drilled, tapped, and inserted using the technique described by Abumi et al ${ }^{[11]}$. Two rods were placed, and morselized cancellous graft harvest from the posterior superior iliac spine were used.

\subsection{Radiologic evaluation}

Radiologic evaluation included standard lateral view of radiographs in a neutral position, which was taken preoperatively, immediate postoperatively and at final follow-up. For every patient, two senior authors performed the measurements twice independently. Measurements were performed using Cobb's technique ${ }^{[13]}$.

$\mathrm{C} 0-\mathrm{C} 2$ lordosis was measured as the angle between the McGregor line and lower endplate of $\mathrm{C} 2$. The measurement of C1-C2 lordosis was calculated between a line connecting the anterior tubercle to the posterior margin of the $\mathrm{C} 1$ spinous process and the inferior end plate of $\mathrm{C} 2$. $\mathrm{C} 2-\mathrm{C} 7$ lordosis was defined as the Cobb angle between the lower endplates of $\mathrm{C} 2$ and $\mathrm{C7}$. $\mathrm{CO}-\mathrm{C} 7$ angle was mesured as the angle between the McGregor line and lower endplate of $\mathrm{C} 7$. The $\mathrm{C} 2-\mathrm{C} 7$ sagittal vertical axis (SVA) was measured as the distance from the posterosuperior corner of $\mathrm{C} 7$ and the vertical line from the center of the $\mathrm{C} 2$ body. The T1 slope (T1S) was the angle formed by the tangent to the upper endplate of $\mathrm{T} 1$ and the horizontal reference line. The neck tilt (NT) was defined as an angle formed by a line drawn in the upper end of the sternum and a line connecting the center of the upper endplate of T1 and the upper end of the sternum. The thoracic inlet angle (TIA) as an angle formed by a line from the center of the T1 upper end plate vertical to the T1 upper end plate and a line connecting the center of the T1 upper end plate and the upper end of the sternum (Fig. 1).

\subsection{Grouping}

At the last follow-up, patients were divided into two groups for further comparison: subaxial lordosis loss group $(n=5)$ and subaxial lordosis increase group $(n=13)$. The subaxial lordosis loss group included the patients whose final follow-up C2-C7 angle was reduced compared with preoperative $\mathrm{C} 2-\mathrm{C} 7$ angle, while the subaxial lordosis increase group included the patients whose final follow-up C2-C7 angle increased.

\subsection{Statistical analysis}

The t-test was used to compare the pre-operative and final follow-up cervical sagittal parameters, and compare the cervical sagittal parameters between two groups before operation and final follow-up. Binary logistic regression was used for continuous data, and Cochran and Mantel-Haenszel chi-squared tests were used for dichotomous data. Univariate and multivariate logistic regression analyses were used to identify potential risk factors. Multivariate logistic regression was performed using variables with $P<0.20$ 
in the univariate analysis. Statistical significance was considered as $P<0.05$. All the statistical analyses were performed using SPSS ver. 16.0 statistical software (SPSS, Chicago, IL, USA).

\section{Results}

A total of 18 patients were included in the review, with an average radiographic follow-up of $8.4 \pm 3.7$ months (range, 6 to 17 months). Overall, subaxial lordosis loss was observed in 5 cases (27.8\%) at the final follow-up, whereas 13 cases had an increase of subaxial lordosis. The comparison of the cervical sagittal parameters between pre-operation and final follow-up is shown in table 1 . There were no significant changes in $\mathrm{C} 0-\mathrm{C} 2$ angle, $\mathrm{C} 2-\mathrm{C} 7$ angle, $\mathrm{C}-\mathrm{C} 7$ angle, $\mathrm{C} 1-\mathrm{C} 2$ angle, $\mathrm{C} 2-\mathrm{C} 7 \mathrm{SVA}, \mathrm{T} 1 \mathrm{~S}, \mathrm{NT}$, and TIA at the last follow-up and pre-operative $(P>0.05)$.

The cervical sagittal parameters of preoperative and final follow-up between two groups were compared, the preoperative $\mathrm{C} 2-\mathrm{C} 7$ angle of the subaxial lordosis loss group was bigger than the subaxial lordosis increase group $\left(27.6^{\circ} \pm 10.5^{\circ}\right.$ vs $\left.10.5^{\circ} \pm 10.5^{\circ}, \mathrm{P}<0.05\right)$, but there was no statistical difference in other parameters (Table 2). Univariate chi-square analysis showed that reduction of subaxial lordosis after posterior atlantoaxial fusion was associated with preoperative $\mathrm{C} 2-\mathrm{C} 7$ angle $\geq 20^{\circ}\left(\chi^{2}=4.923, \mathrm{P}=0.026\right)$. However, logistic regression analysis showed that the preoperative $\mathrm{C} 2-\mathrm{C} 7$ angle $\geq 20^{\circ}$ was not an independent risk factor $(O R=0.147, P=0.225)$. These results were illustrated in Tables 3,4 . A typical case was shown in Fig. 2.

\section{Discussion}

Cervical sagittal balance plays a decisive role in maintaining the biomechanical properties and normal motor functions of the cervical spine. Although clinical outcomes of posterior atlantoaxial fusion were satisfactory, postoperative cervical sagittal imbalance may be one of the causes of postoperative pain and function loss. More recently, restoring sagittal alignment of cervical spine has received increasing attention, correlating with preoperative surgical planning and postoperative outcomes evaluating.

Parameters used to evaluate the sagittal aligment of the cervical spine include $\mathrm{C} 0-\mathrm{C} 2$ angle, $\mathrm{C} 1-\mathrm{C} 2$ angle, C2-C7 angle, SVA, T1S, NT and TIA ${ }^{[14-16]}$. There is certain correlation between parameters, the mathematical relationship between these parameters is described by: TIA = T1S + NT. TIA is constant, and theT1S and NT are positional. TIA remains stable with increasing age during adulthood, and does not change with postural, position or spinal degeneration. T1S changes with SVA and kyphotic curvature of the upper thoracic spine. To prevent or limit sagittal imbalance, the cervical spine may also compensate by increasing NT and decreasing T1S in an attempt to maintain horizontal gaze. There were negative correlations between $\mathrm{C} 1-\mathrm{C} 2$ angle and C2-C7 angle as well as between C0-C2 angle and C2-C7 angle in patients with atlantoaxial instability or dislocation. And the negative correlations remain in patients who underwent posterior atlantoaxial fusion ${ }^{[1,9,17]}$. In this study, no significant changes of the cervical sagittal parameters were noted between the last follow-up and before surgery. Therefore, we believe that the posterior atlantoaxial fusion for atlantoaxial dislocation does not affect the cervical sagittal parameters. 
The class boundaries of each factors in the univariate analysis of this study were determined mainly by reference to previous research results. Iyer et al. ${ }^{[18]}$ retrospectively analyzed 120 American adult volunteers without cervical and back symptoms, and measured that the average TIA was about $79.8^{\circ}$ and T1S was $26.1^{\circ}$. Lee et al. ${ }^{[19]}$ measured an average TIA of $69.5^{\circ}$ and T1S of $25.7^{\circ}$ in 77 asymptomatic Korean adult volunteers. Based on the measurement results of the above studies, $70^{\circ}$ was chosen as the class boundary for preoperative TIA and $25^{\circ}$ for preoperative T1S. Lee et al. ${ }^{[19]}$ measured an average C0$\mathrm{C} 2$ of about $22.4^{\circ}$ and C2-C7 of $9.9^{\circ}$ in 77 asymptomatic Korean adult volunteers. Hardacker et al. ${ }^{[20]}$ studied 100 healthy American adults and found that the $\mathrm{C} 0-\mathrm{C} 2$ angle averaged about $30^{\circ}$ and the $\mathrm{C} 2-\mathrm{C} 7$ angle averaged about $9.6^{\circ}$. Harrison et al. measured $\mathrm{C} 2-\mathrm{C} 7$ angle of $17^{\circ}$ and $26^{\circ}$ by Cobb method and Harrison posterior tangent method on thirty lateral cervical radiographs. Based on these measurement results, the preoperative $\mathrm{C} 2-\mathrm{C} 7$ angle, preoperative $\mathrm{C} 0-\mathrm{C} 2$ angle and preoperative $\mathrm{C} 0-\mathrm{C} 7$ angle were selected as the boundary of $20^{\circ}, 20^{\circ}$ and $45^{\circ}$ respectively. The C2-C7 SVA of normal healthy adults is about $20 \mathrm{~mm}$, but there are differences between people of different ages: $28.5 \mathrm{~mm}$ for adults aged 20 to 39 years, $18.2 \mathrm{~mm}$ for adults aged 40 to 59 years, $-22.4 \mathrm{~mm}$ for adults aged 60 years or older ${ }^{[7,8]}$. Regarding the age distribution of our study (average age of 49.6 years), $15 \mathrm{~mm}$ was chosen as the class boundary for preoperative C2-C7 SVA. To maintain the physiologic sagittal alignment of the subaxial cervical spine, $\mathrm{C} 1-\mathrm{C} 2$ should be fixed at an optimal fusion angle of $10^{\circ}-20^{\circ}$. When the fusion angles of $\mathrm{C} 1-$ C2 were more than $20^{\circ}$, the subaxial lordosis would be insufficient, resulting in degeneration of the lower cervical disc. There was a linear negative association between the $\mathrm{C} 1-\mathrm{C} 2$ fixation angle and the $\mathrm{C} 2-\mathrm{C} 7$ postoperative angle. Therefore, $20^{\circ}$ was chosen as the class boundary for the postoperative $\mathrm{C} 1-\mathrm{C} 2$ angle.

Studies have suggested that abnormal changes of lower cervical curvature after atlantoaxial fusion may be related to age, C1-C2 fixation angle and internal fixation techniques. Passias et al. ${ }^{[21]}$ found that age was an important independent factor and negatively correlated with the changes in the curvature of the lower cervical spine after atlantoaxial fusion, which may be due to the fact that the lower cervical spine is more flexible in young people, so that the lower cervical spine can better compensate for the changes in the upper cervical spine, so as to ensure the local balance of the cervical spine. However, the results of this study showed that there was no significant correlation between age and subaxial lordosis loss.

Toyama et al. ${ }^{[2]}$ found that postoperative cervical kyphosis or swan-neck deformity occurred if C1-C2 fixation angle exceeded $30^{\circ}$. Kato et al. ${ }^{[22]}$ retrospectively analyzed the relation between the preoperative C1-C2 angle and C2-C7 angle in 28 consecutive rheumatoid arthritis patients, and found that complete or overreduction of the $\mathrm{C} 1-\mathrm{C} 2$ angle may cause reduced $\mathrm{C} 2-\mathrm{C} 7$ angle and cervical malalignment (lordosis loss, kyphosis, and swan-neck deformity) in patients with a preoperative C1-C2 angle of $<20$ degrees. However, the results of this study suggest that postoperative C1-C2 angle didn't affect subaxial cervical aligment. Atlantoaxial transarticular facet screw fixation (Magerl technique) and C1 lateral mass screws combined with $\mathrm{C} 2$ pedicle screws fixation (Harms technique) are the most commonly used techniques for posterior internal fixation in the upper cervical spine. Studies showed that Magerl technique combined with posterior titanium atlantoaxial cable fixation was more likely to cause excessive lordosis position of C1-C2 than Harms technique, resulting postoperative kyphosis deformity of the lower cervical spine. 
Therefore, we chose Harms technique to reduce the occurrence of postoperative kyphosis deformity. In this study, the univariate Chi-square analysis showed that postoperative subaxial lordosis was negatively correlated with preoperative $\mathrm{C} 2-\mathrm{C} 7$ angle, that is, preoperative $\mathrm{C} 2-\mathrm{C} 7$ angle $\geq 20^{\circ}$ could easily cause postoperative loss of subaxial lordosis. A large preoperative $\mathrm{C} 2-\mathrm{C} 7$ angle would lead to a small preoperative $\mathrm{C} 1-\mathrm{C} 2$ angle in an attempt to maintain horizontal gaze. There were negative correlations between $\mathrm{C} 1-\mathrm{C} 2$ angle and $\mathrm{C} 2-\mathrm{C} 7$ angle ${ }^{[1,9,17]}$, thus partial reduction of the $\mathrm{C} 1-\mathrm{C} 2$ angle after posterior atlantoaxial fusion (increased from $12.4^{\circ}$ preoperatively to $17.5^{\circ}$ postoperatively ) may cause reduce of $\mathrm{C} 2-\mathrm{C} 7$ angle. Howerver, the multivariate logistic regression analysis in this study showed that the preoperative $\mathrm{C} 2-\mathrm{C} 7$ Angle $\geq 20^{\circ}$ was not an independent risk factor ( $\left.\mathrm{OR}=0.147, \mathrm{P}=0.225\right)$, indicating that there may be other factors affecting the postoperative loss of subaxial lordosis. Limitations of the study include the small sample size, lack of long-term follow-up. Furthermore, whether postoperative pain or muscle stiffness has an impact on the results needs to be further clarified.

In conclusion, our study demonstrated that subaxial lordosis loss may occur after posterior atlantoaxial fusion, and preoperative $\mathrm{C} 2-\mathrm{C} 7$ angle $\geq 20^{\circ}$ was a risk factor of postoperative loss of subaxial lordosis. To avoid postoperative cervical malalignment for patients with atlantoaxial dislocation, more attention should be paid to fully consider the age, etiology and other factors before surgery, determine the appropriate atlantoaxial fixation angle and surgical technique.

\section{Declarations}

\section{Ethics approval and consent to participate}

This article does not contain any studies with human participants or animals performed by any of the authors.

\section{Consent for publication}

Written informed consent for publication was obtained from all participants.

\section{Availability of data and materials}

All data are available on request.

\section{Competing interests}

The authors declare that they have no competing interests.

\section{Funding}

No funding has been received for the study.

\section{Authors' contributions}


SQL conceived and designed the study; SQL and BLL collected the data; QYC, HFW and YHL analyzed and interpreted the patient data. SQL and GQL wrote the paper. All authors read and approved the final manuscript.

All authors have read the journal policies and have no issues relating to journal policies. All authors have seen the manuscript and approved to submit to your journal. The work described has not been submitted elsewhere for publication, in whole or in part.

\section{Acknowledgements}

Not applicable.

\section{References}

1. Yoshida G, Kamiya $M$, Yoshihara $H$, et al. Subaxial sagittal alignment and adjacent-segment degeneration after atlantoaxial fixation performed using C-1 lateral mass and C-2 pedicle screws or transarticular screws[J]. J Neurosurg Spine, 2010, 13(4): 443-450. DOI: 10.3171/2010.4.SPINE09662.

2. Toyama $Y$, Matsumoto $M$, Chiba $K$, et al. Realignment of postoperative cervical kyphosis in children by vertebral remodeling[J]. Spine (Phila Pa 1976), 1994, 19(22): 2565-2570. DOI:

3. Mukai Y, Hosono N, Sakaura H, et al. Sagittal alignment of the subaxial cervical spine after C1-C2 transarticular screw fixation in rheumatoid arthritis[J]. J Spinal Disord Tech, 2007, 20(6): 436-441. DOI:

4. Kang D, Lehman R, Wagner S, et al. Subaxial cervical sagittal alignment following C1-C2 fusion for atlanto-axial osteoarthritis[J]. Global Spine J, 2015, 05(S01): s-0035-1554386. DOI:

5. Lippa L, Cacciola F. Loss of cervical lordosis: What is the prognosis?[J]. J Craniovertebr Junction Spine, 2017, 8(1): 9-14. DOI: 10.4103/0974-8237.199877.

6. Kaptain GJ, Simmons NE, Replogle RE, et al. Incidence and outcome of kyphotic deformity following laminectomy for cervical spondylotic myelopathy[J]. J Neurosurg, 2000, 93(2 Suppl): 199-204. DOI:

7. Scheer JK, Tang JA, Smith JS, et al. Cervical spine alignment, sagittal deformity, and clinical implications: a review[J]. J Neurosurg Spine, 2013, 19(2): 141-159. DOI: 10.3171/2013.4.SPINE12838.

8. Tang JA, Scheer JK, Smith JS, et al. The impact of standing regional cervical sagittal alignment on outcomes in posterior cervical fusion surgery[J]. Neurosurgery, 2012, 71(3): 662-669; discussion 669. DOI: 10.1227/NEU.0b013e31826100c9.

9. Passias PG, Wang $S$, Kozanek M, et al. Relationship between the alignment of the occipitoaxial and subaxial cervical spine in patients with congenital atlantoxial dislocations[J]. J Spinal Disord Tech, 2013, 26(1): 15-21. DOI: 10.1097/BSD.0b013e31823097f9.

10. Clarke MJ, Cohen-Gadol AA, Ebersold MJ, et al. Long-term incidence of subaxial cervical spine instability following cervical arthrodesis surgery in patients with rheumatoid arthritis[J]. Surg Neurol, 2006, 66(2): 136-140; discussion 140. DOI: 10.1016/j.surneu.2005.12.037. 
11. Abumi K, Takada T, Shono Y, et al. Posterior occipitocervical reconstruction using cervical pedicle screws and plate-rod systems[J]. Spine (Phila Pa 1976), 1999, 24(14): 1425-1434. DOI:

12. Wang $S$, Wang $C$, Yan $M$, et al. Novel surgical classification and treatment strategy for atlantoaxial dislocations[J]. Spine (Phila Pa 1976), 2013, 38(21): E1348-1356. DOI: 10.1097/BRS.0b013e3182a1e5e4.

13. Gore DR, Sepic SB, Gardner GM. Roentgenographic findings of the cervical spine in asymptomatic people[J]. Spine (Phila Pa 1976), 1986, 11(6): 521-524. DOI: 10.1097/00007632-198607000-00003.

14. Nojiri K, Matsumoto M, Chiba K, et al. Relationship between alignment of upper and lower cervical spine in asymptomatic individuals[J]. J Neurosurg, 2003, 99(1 Suppl): 80-83. DOI:

15. Guo Q, Ni B, Yang J, et al. Relation between alignments of upper and subaxial cervical spine: a radiological study[J]. Arch Orthop Trauma Surg, 2011, 131(6): 857-862. DOI: 10.1007/s00402-011$1265-\mathrm{x}$.

16. Sherekar SK, Yadav YR, Basoor AS, et al. Clinical implications of alignment of upper and lower cervical spine[J]. Neurol India, 2006, 54(3): 264-267. DOI:

17. Oshima $S$, Sudo $H$, Ito $M$, et al. Subaxial sagittal alignment after atlantoaxial fixation techniques[J]. J Spinal Disord Tech, 2015, 28(1): E49-55. DOI: 10.1097/BSD.0000000000000144.

18. Iyer S, Lenke LG, Nemani VM, et al. Variations in Occipitocervical and Cervicothoracic Alignment Parameters Based on Age: A Prospective Study of Asymptomatic Volunteers Using Full-Body Radiographs[J]. Spine (Phila Pa 1976), 2016, 41(23): 1837-1844. DOI:

10.1097/BRS.0000000000001644.

19. Lee SH, Kim KT, Seo EM, et al. The influence of thoracic inlet alignment on the craniocervical sagittal balance in asymptomatic adults[J]. J Spinal Disord Tech, 2012, 25(2): E41-47. DOI:

10.1097/BSD.0b013e3182396301.

20. Hardacker JW, Shuford RF, Capicotto PN, et al. Radiographic standing cervical segmental alignment in adult volunteers without neck symptoms[J]. Spine (Phila Pa 1976), 1997, 22(13): 1472-1480; discussion 1480. DOI:

21. Passias $P G$, Wang $S$, Zhao $D$, et al. The reversibility of swan neck deformity in chronic atlantoaxial dislocations[J]. Spine (Phila Pa 1976), 2013, 38(7): E379-385. DOI:

10.1097/BRS.0b013e31828625e4.

22. Kato $\mathrm{Y}$, Itoh $\mathrm{T}$, Kanaya $\mathrm{K}$, et al. Relation between atlantoaxial (C1/2) and cervical alignment (C2-C7) angles with Magerl and Brooks techniques for atlantoaxial subluxation in rheumatoid arthritis[J]. J Orthop Sci, 2006, 11(4): 347-352. DOI: 10.1007/s00776-006-1033-x.

\section{Tables}

Tables 1-4 are not available with this version.

\section{Figures}




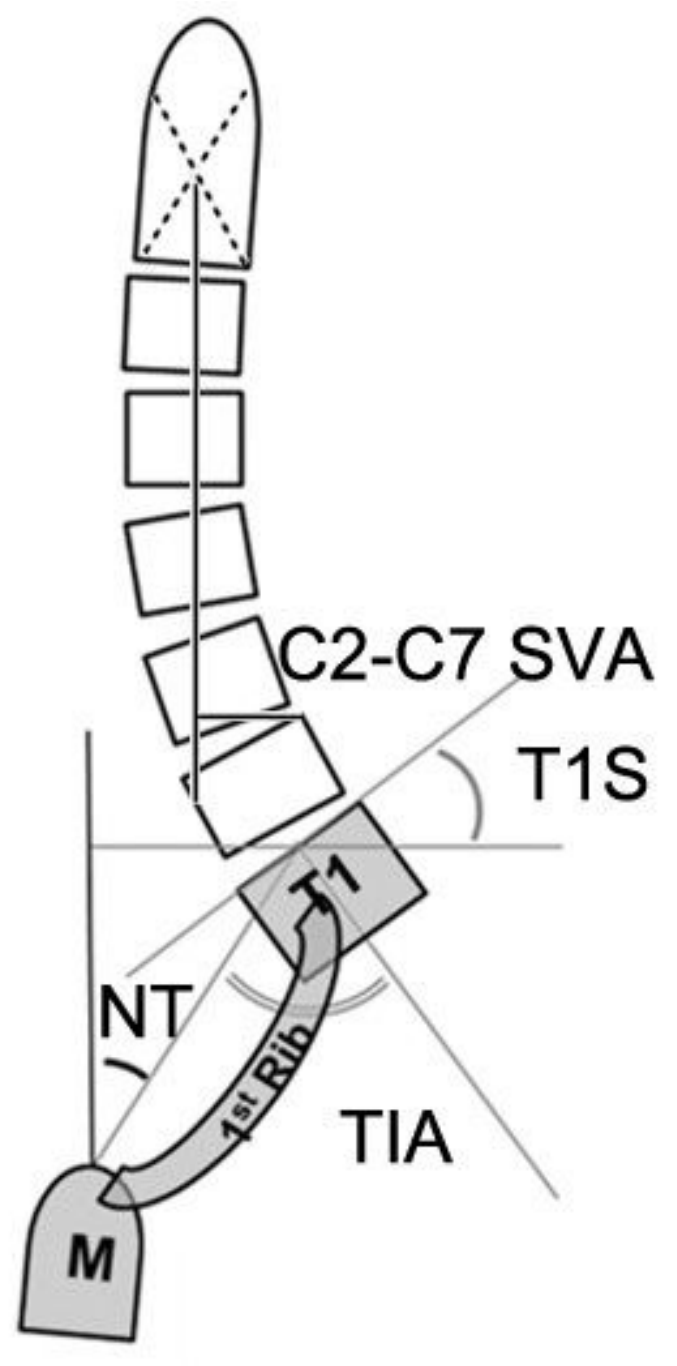

Figure 1

Cervical sagittal parameters (C2-C7 SVA, C2-C7 sagittal vertical axis; T1S, T1 slope; NT, neck tilt; TIA, thoracic inlet angle; T1, first thoracic vertebra; $M$, manubrium; 1st Rib, first rib) 

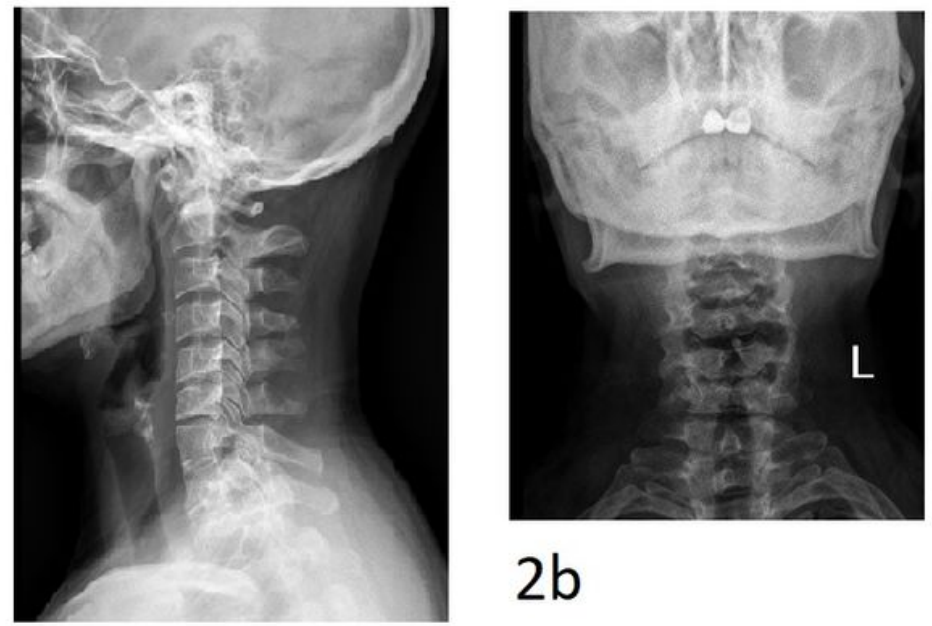

$2 b$

$2 a$

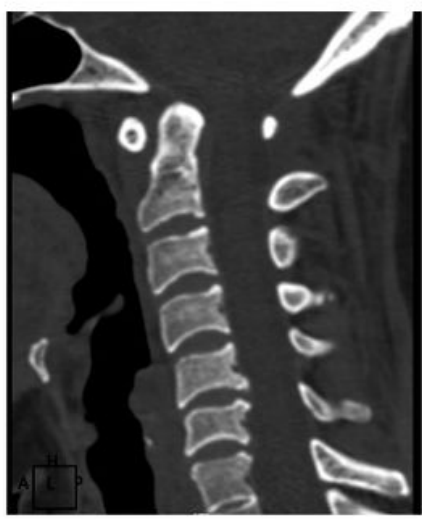

$2 e$

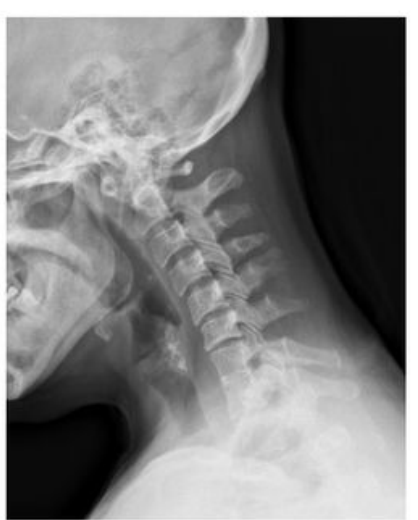

$2 c$

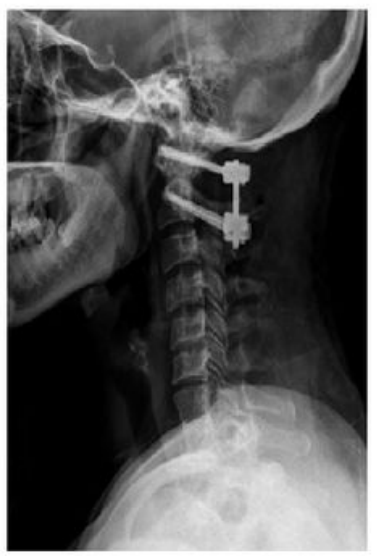

$2 \mathrm{~g}$

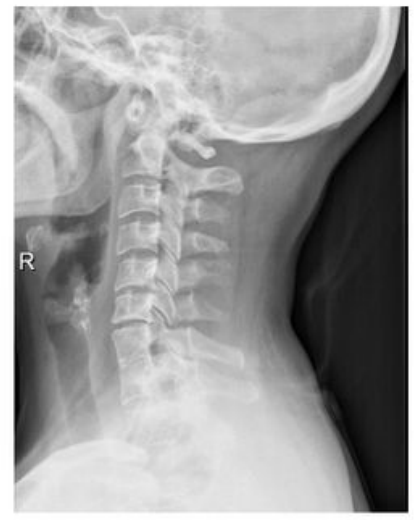

$2 d$

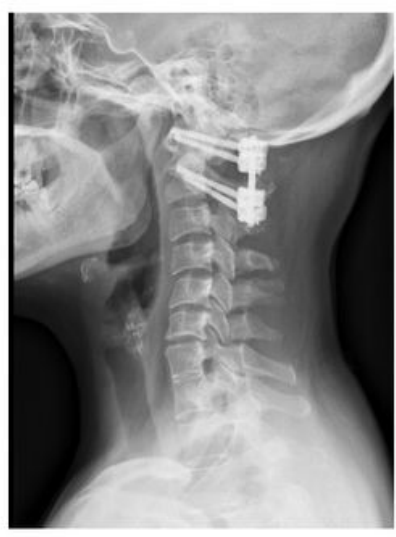

$2 \mathrm{~h}$

\section{Figure 2}

Atlantoaxial dislocation (Type II), female, 51 years old a, b Lateral and open-mouth view radiographs of cervical spine showed that the $\mathrm{C} 2-\mathrm{C} 7$ angle was $8^{\circ} \mathrm{C}$, $\mathrm{d}$ Flexion-extension radiographs of cervical spine indicated a partially reducable dislocation of the atlantoaxial joint e, $\mathrm{f}$ CT scan of cervical spine also indicated the atlantoaxial dislocation g One month after operation, lateral radiograph of cervical spine showed that the dislocation had been fully reduced, and the C2-C7 angle was $8^{\circ} \mathrm{h}$ Seven months after operation, lateral radiograph of cervical spine showed the loss of subaxial lordosis and the C2-C7 angle was $2^{\circ}$ 